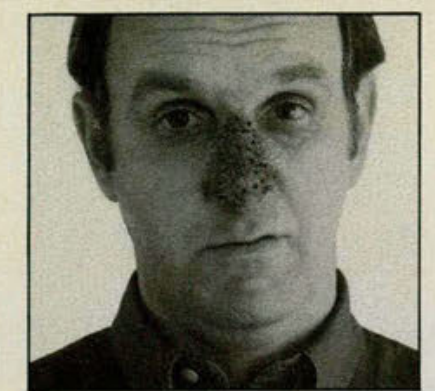

Antihistamines can have an overwhelming effect on sinusitis.

CUAIFED ${ }^{\circledR}$ Capsules (pseudoephedrine $\mathrm{HCl} 120 \mathrm{mg}$
and guaifenesin $250 \mathrm{mg}$ )

CIIAIFE-PD Capsules (pseudoephedrine $\mathrm{HCl} 60 \mathrm{mg}$ and guaifenesin $300 \mathrm{mg}$ )

Brief Summary

CONTRAINDICATIONS: This product is contraindicated in patients with a known hypersensitivity to any of its ingredients. Also contraindicated in patients with severe hypertension, severe coronary artery disease and patients on MAO inhibitor therapy. Should not be used during pregnancy or in nursing mothers.

Considerable caution should be exercised in patients with hypertension, diabetes mellitus, ischemic heart disease, hyperthyroidism, increased intraocular pressure and prostatic hypertrophy. The elderly ( 60 years or older) are more likely to exhibit adverse reactions. At dosages higher than the recommended dose, nervousness, dizziness or sleeplessness may occur.

PRECAUTIONS: General: Caution should be exercised in patients with high blood pressure, heart disease, diabetes or thyroid disease and in patients who exhibit difficulty in urination due to enlargement of the prostate gland. Check with a physician if symptoms do not improve within 7 days or if accompanied by high fever, rash or persistent headache. Drug Interactions: Do not take this product if you are presently taking a prescription drug for high blood pressure or depression, without first consulting a physician. MAO inhibitors and beta adrenergic blockers may increase the effect of sympathomimetics. Sympathomimetics may reduce the antihypertensive effects of methyldopa, mecamylamine. reserpine and veratrum alkaloids. $P$ seudoephedrine hydrochloride may increase the possibility of cardiac arrhythmias in patients presently taking digitalis glycosides.

Pregnancy: Pregnancy Category B. It has been shown that pseudoephedrine hydrochloride can cause reduced average weight, length, and rate of skeletal ossification in the animal fetus.

Nursing Mothers: Pseudoephedrine is excreted in breast milk; use by nursing mother is not recommended because of the higher than usual risk of side effects from sympathoture infants.

Geriatrics: Pseudoephedrine should be used with caution in the elderly because they may be more sensitive to the effects of the sympathomimetics.

WARNINGS: Do not take this product for persistent or chronic cough such as occurs with smoking asthma or emphysema, or where cough is accompanied by excessive emphysema, or where cough is accompanied by excessive physician. This medication should be taken a few hours prior to bedtime to minimize the possibility of sleeplessness. Take this medication with a glass of water after each dose, to help loosen mucus in the lungs.

ADVERSE REACTIONS: Adverse reactions include nausea, cardiac palpitations, increased irritability or excite. ment, headache, dizziness, tachycardia, diarrhea, drowsiness stomach pain seizures, slowed heart rate shortness of breath and/or troubled breathing.

DOSAGE AND ADMINISTRATION: GUAIFED* CAP. SULES Adults and children over 12 years of age: 1 cap. sule every 12 hours.

GUAIFED-PD* CAPSULES Adults and children over 12 years of age: 1 or 2 capsules every 12 hours. Children 6 to 12 years of age: 1 capsule every 12 hours.

CAUTION: FEDERAL (U.S.A.) LAW PROHIBITS DISPENSING WITHOUT A PRESCRIPTION.

\section{Distributed by}

\section{Muro}

Pharmaceutical, Inc.

Tewksbury, MA 01876-9987

\title{
New members
}

Appel, Daniel M, UHSCOM '80; 3089 Winchester Rd, West Bloomfield, MI 48322-2411

Beard, Gregory K, UHSCOM '87; Kennedy Mem Hosp/Univ Med Ctr, 113 E Laurel Rd, Stratford, NJ 08084-1324

Bowling, Robert Lee, TCOM '85; 3135 Saba Ln, Port Neches, TX 77651-5421

Brandau, Duane T, UOMHS '78; KCOM, 800 W Jefferson St, Kirksville, MO 63501-1443

Campbell, Robert, TCOM '83; 103 W Ridge Rd, Weatherford, TX 76086-5164

Cawthon, Deborah H, TCOM '86; 806 Thomasson, Dallas, TX 75208-3954

Chenoweth, John R, UHSCOM '70; 9601 Metcalf, Brookridge, KS $66212-2218$

Dinsmore, Steven, PCOM '82; 638 Park Dr, Cherry Hill, NJ 08002

DiSanti, Steve J, CCOM '82; 109 S Genoa St, Genoa, IL 601351120

Felber, Karl, UNECOM '88; 46 Harrison St, Cumberland, RI 02864-7418

Greenly, Gary Lee, PCOM '84; Niu Valley Shopping Center, 549 Halemaumau St, Honolulu, HI 96821
Hassman, Elissa F, PCOM '86; No 3304,1730 N Clark St, Chicago, IL 60614-5858

Havens, Eric S, WVSOM ' 85 ; 3143 Searsmont Pl, Herndon, VA 22071-1901

Hild, Deborah Ann, CCOM '84; 13205 W 143rd St, Lockport, IL 60441-8388

Hunt, Robert F, NYCOM '85; 713 N State Rd 7, Hollywood, FL 33021-5602

Kaatz, Scott, MSUCOM '83; 1078 Prosper Dr, Troy, MI 480982026

Lozito, Deborah Ann, PCOM '87; 18 Boonstra Dr, Wayne, NJ 07470-2528

Lyons, Michael J, PCOM '75; PO Box 741, Kirksville, MO 63501

Marcoe, Gregory, MSUCOM '87; 4087 Old Pine Tree, Midland, MI 48642

Michalsen, Thomas, CCOM '82; 406 S 5th St, Kirkland, IL 60146

Morales, Robert, UHSCOM ' 81 ; 13201 Walsingham Rd, Largo, FL 34644

Royder, Clayton Howard, TCOM '86; 867 W Town St, Columbus, $\mathrm{OH} 43222$

Thiele, Kim E, KCOM '80; 521 $\mathrm{N} 5$ th St, Marietta, OH 45750-1909 


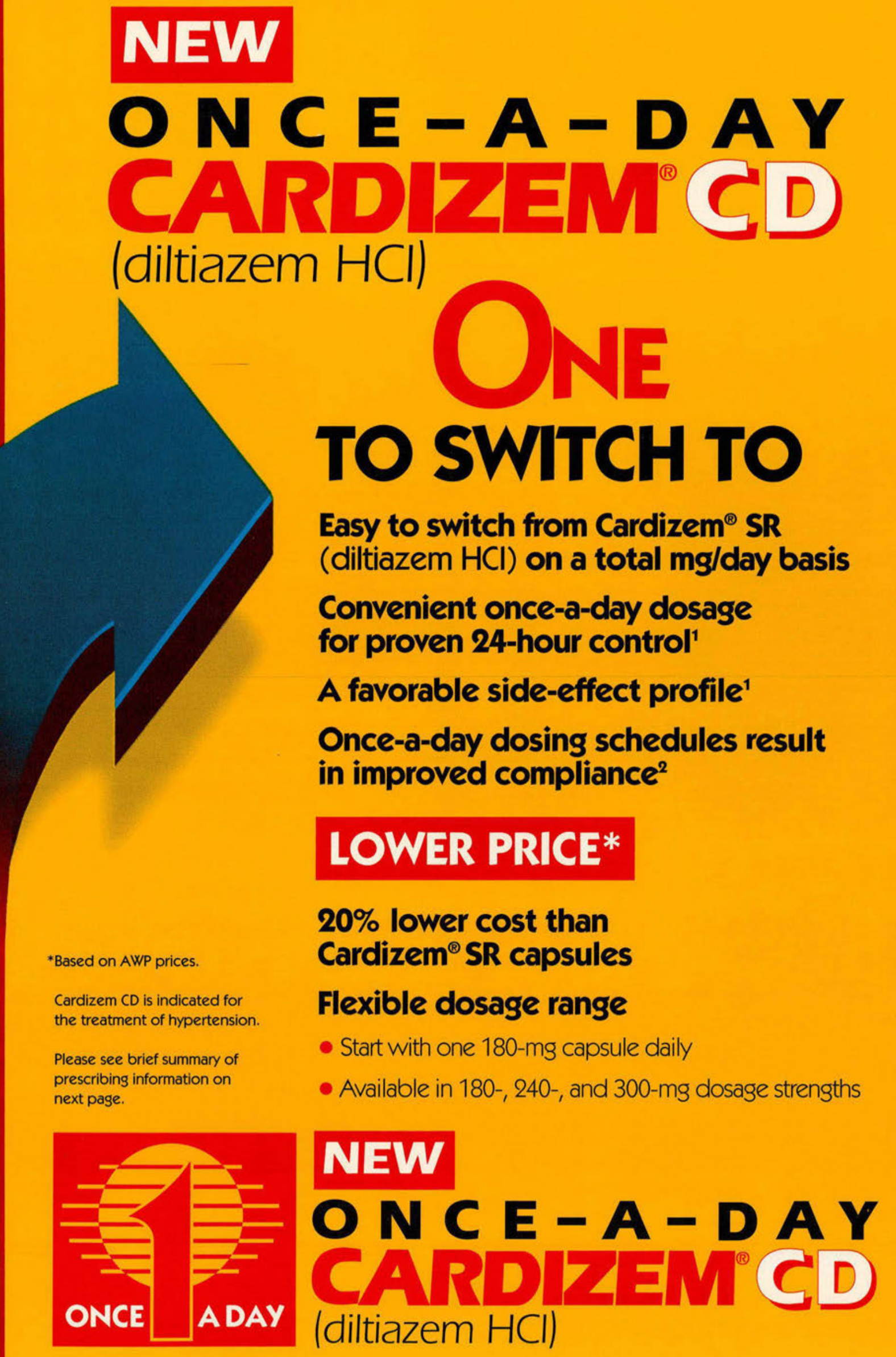




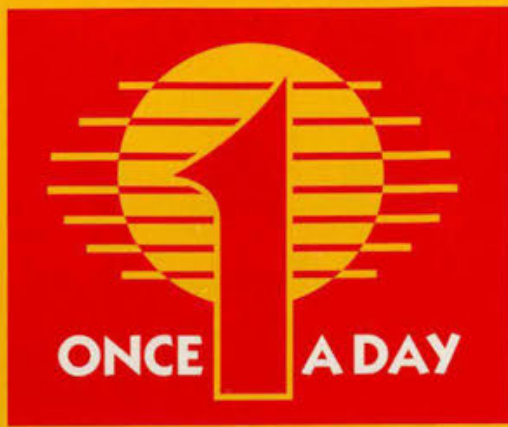

\section{NEW}

\section{O N C E - A - D A Y CARDTLEN CD (diltiazem HCl)}

\section{Switch from Cardizem ${ }^{\oplus}$ SR on a total $\mathrm{mg} /$ day basis For new patients starting on Cardizem ${ }^{\circledR}$ CD:}

- Start with one 180-mg capsule daily

- Monitor for 2 weeks; if optimal response is not met

- Titrate to goal blood pressure

\section{BRIEF SUMMARY}

CARDIZEMO CD (dilitiazem hydrochloride) Capsules

CARDIZEMO SR (diltiazem hydrochloride) Sustained Release Capsules CONTRAINDICATIONS

CARDIZEM is contraindicated in (1) patients with sick sinus smdrome except in the presence of a functioning ventricular pacemaker, (2) patients with second- or third-degree AV block except in the presence of a functioning ventricular pacemaker, (3) patients with hypotension (less than $90 \mathrm{~mm} \mathrm{Hg}$ systolic), (4) patients who have demonstrated hypersensitivity to the drug, and (5) patients with acute myocardial infarction and pulmonary congestion documented by $X$-ray on admission.

WARNINGS

1. Cardiac Conduction. CARDIZEM prolongs AV node refractory periods without significantly prolonging sinus node recovery time, except in patients with sick sinus syndrome. This effect may rarely result in abnormally slow heart rates (particularly in patients with sick sinus syndrome) or second- or third. degree AV block ( 13 of 3,007 patients or $0.43 \%$ ). Concomitant us? of diltiazem with beta-blockers or digitalis may result in additive effects on cardiac conduction. A patient with Prinzmetal's angina developed periods of asystole ( 2 to 5 seconds) after a single dose of 60 mg of dilitiazem.

2. Congestive Heart Failure. Although diltiazem has a negative inotropic effect in isolated animal tissue preparations, hemodynamic studies in humans with normal ventricular function have not shown a reduction in cardiac index nor consistent negative effects on contractility (dp/dt). An acute study of ora diltiazem in patients with impaired ventricular function (ejection fraction $24 \%$ $\pm 6 \%$ ) showed improvement in indices of ventricular function without significant decrease in contractile function (dp at). Worsening of congestive heart failure has been reported in patients with preexisting impairment of ventricular function. Experience with the use of CARDIZEM in combination with beta-blockers in patients with impaired ventricular
Caution should be exercised when using this combination.

Caution should be exercised when using this combination.

3. Hypotension. Decreases in blood pressure associated with CARDIZEM therapy may occasionally result in symptomatic hypotension

4. Acute Hepatic Injury. Mild elevations of transaminases with and without concomitant elevation in alkaline phosphatase and bilinubin have been observed in clinical studies. Such elevations were usually transient and frequently resolved even with continued diltiazem treatment. In rare instances, significant elevations in enzymes such as alkaline phosphatase, IDH SGOI, SGPT, and other phenomena consistent with acute hepatic injury have been noted. These reactions tended to occur early after therapy intiation (1 to 8 weeks) and have been reversible upon discontinuation of drug therapy. The relationship to CARDIZEM is uncertain in some cases, but probable in some. (See PRECAUTIONS)

PRECAUTIONS

General. CARDIZEM is extensively metabolized by the liver and excreted by the kidneys and in bile. As with any drug given over prolonged periods, laboratory parameters should be monitored at regular intervals. The drus should be used with caution in patients with impaired renal or hepatic function. In subacute and chronic dog and rat studies designed to produce toxicity, high doses of diltiazem were associated with hepatic damage. In special subacute hepatic studies, oral doses of $125 \mathrm{mg} / \mathrm{kg}$ and higher in rats were associated with histological changes in the liver which were reversible when the drug was discontinued. In dogs, doses of $20 \mathrm{mg} / \mathrm{kg}$ were also associated with hepatic changes; however, these changes were reversible with continued dosing.

Dermatological events (see ADVERSE REACTIONS section) may be transient and may disappear despite continued use of CARDIZEM. However, skin enuptions progressing to erythema multiforme and or exoliative dermatitis have also been infrequenty reported. Should a dermatologic reaction persist, the drus

Drug Interaction. Due to the potential for additive effects, caution and careful tutation are warranted in patients receiving CARDIZEM concomitanty with any agents known to affect cardiac contractility and/or conduction. (See
WARNINGS.) Pharmacologic studies indicate that there may be additive effects in prolonging AV conduction when using beta-blockers or digitalis concomitantly with CARDIZEM. (See WAPNINGS.)

As with all drugs, care should be exercised when treating patients with multiple medications. CARDZZEM undergoes biotransformation by crtochrome agents which follow the same. Coadministration of CARDIZEM with other competitive inhibition of metabolism. Dosages of similaty metabolized dings such as cyclosporin, particularty those of low therapeutic ratio or in patients with renal and/or hepatic impaiment, may require adjustment when starting or stopping concomitantly administered CARDIZEM to maintain optimum therapeutic blood levels.

Beta-blockers: Controlled and uncontrolled domestic studies sugsest that concomitant use of CARDIZEM and beta-blockers is usually well tolerated, but available data are not sufficient to predict the effects of concomitant treatment in patients with left ventricular dysfunction or cardiac conduction

Administration of CARDIZEM (diltiazem hydrochloride) concomitantly with propranolol in five normal volunteers resulted in increased propranolol levels in all subjects and bioavalability of propranolol was increased approximately $50 \%$. If combination therapy is initiated or withdrawn in conjunction with propranolol, an adjustment in the propranolol dose may be warranted. (See WARNINGS

Cimetidine: A study in six healthy volunteers has shown a significant increase in peak ditiazem plasma levels $(58 \%)$ and area-under-the-curve $(53 \%)$ after o 1-week course of cimetidine at $1,200 \mathrm{mg}$ per day and diltiazem $60 \mathrm{~ms}$ per day. Ranitidine produced smaller, nonsignificant increases. The effect may be mediated by cimetidine's known inhibition of hepatic cytochrome P-450, the enzyme system probably responsible for the first-pass metabolism of diltiazem. Patients currently receiving diltiazem therapy should be carefully monitored for a change in pharmacological effect when initiating and discontinuing therapy with cimetidine. An adjustment in the diltiazem dose may be warranted.

Digitalis: Administration of CARDIZEM with digoxin in 24 healthy male subjects increased plasma digoxin concentrations approximately $20 \%$. Another investigator found no increase in digoxin levels in 12 patients with coronary artery disease. Since there have been conflicting results regarding the effect of digoxin levels, it is recommended that digoxin levels be monitored when initiating, adjusting, and discontinuing CARDIZEM therapy to avoid possible over-or under-digtalization. (See WARNINGS.

Anesthetics: The depression of cardiac contractility, conductivity, and automaticity as well as the vascalar dilation associated with anesthetics may be potentiated by calcium channel blockers. When used concomitantly, anesthetics and calcium blockers should be titrated carefully.

Carcinogenesis, Mutagenesis, Impairment of Fertility. A 24-month study in rats at oral dosage levels of up to $100 \mathrm{mg} \mathrm{kg}$ day, and a 21 -month study in mice at oral dosage levels of up to $30 \mathrm{mg} / \mathrm{kg}$ day showed no evidence of carcinogenicity. There was also no mutagenic response in vitro or in vivo in mammalian cell assays or in vitro in bacteria. No evidence of impaired fertility was obsenved in a study performed in male and female rats at oral dosages of up to $100 \mathrm{mg} / \mathrm{kg}$ day.

Pregnancy. Category C. Reproduction studies have been conducted in mice, rats, and raboits. Administration of doses ranging from five to ten times greater (on a mg kg basis) than the daily recommended therapeutic dose has resulted in embryo and fetal lethality. These doses, in some studies, have been reported to cause skeletal abnomalities. In the perinatal postnatal studies, there was an increased incidence of stillbirths at doses of 20 times the human dose or greater.

There are no well-controlled studies in pregnant women; therefore, use CARDIZEM in pregnant wor

Nursing Mothers. Diltizen is excreted in humen milk One report surgest that concentrations in breast milk may approximate senum levels if use of CARDIZEM is deemed essential, an altemative method of infant feeding should be instituted.

Pediatric Use. Safety and effectiveness in children have not been established. ADVERSE REACTIONS

Serious adverse reactions have been rare in studies caried out to date, but it should be recognized that patients with impaired ventricular function and cardiac conduction abnormalities have usually been excluded from these studie.

The adverse events described below represent events observed in clinical studies of hypertensive patients receiving either CARDIZEM Tablets or CARDIZEM SR Capsules as well as experiences observed in studies of angina shown ing marketing. The most common events in hypertension studies are common events are listed by body system; these include any adverse reactions seen in angina studies that were not observed in hypertension studies. In al hypertensive patients taking CARDIZEM Tablets or CARDIZEM SR Capsules studied (over 900), the most common adverse events were edema

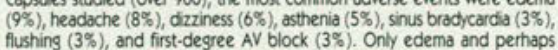
bradicardia and diminess were dose related
DOUBLE BUIND PLACEBO CONTROLLED HYPERTENSION TRIALS

\begin{tabular}{|c|c|c|}
\hline ADVERSE & $\begin{array}{c}\text { DILTIAZEM } \\
N=315 \\
\neq \mathrm{PTS}(\%)\end{array}$ & $\begin{array}{c}\text { PLACEBO } \\
\text { N=211 } \\
\text { PTS (\%) }\end{array}$ \\
\hline Headache & $38(12 \%)$ & $17(8 \%)$ \\
\hline AV Block First Degree & $24(7.6 \%)$ & $4(1.9 \%)$ \\
\hline Dizziness & $22(7 \%)$ & $6(2.8 \%)$ \\
\hline Edema & $19(6 \%)$ & $2(0.9 \%)$ \\
\hline Bradycardia & $19(6 \%)$ & $3(1.4 \%)$ \\
\hline ECG Abnormality & $13(4.1 \%)$ & $3(1.4 \%)$ \\
\hline Asthenia & $10(3.2 \%)$ & $1(0.5 \%)$ \\
\hline Constipation & $5(1.6 \%)$ & $2(0.9 \%)$ \\
\hline Dyspepsia & $4(1.3 \%)$ & $1(0.5 \%)$ \\
\hline Nausea & $4(1.3 \%)$ & $2(0.9 \%)$ \\
\hline Palpitations & $4(1.3 \%)$ & $2(0.9 \%)$ \\
\hline $\begin{array}{l}\text { Polyuria } \\
\text { Pas }\end{array}$ & $4(1.3 \%)$ & $2(0.9 \%)$ \\
\hline Somnolence & $4(13 \%)$ & \\
\hline Alk Phos Increase & $3(1 \%)$ & $1(0.5 \%)$ \\
\hline Hypotension & $3(1 \%)$ & $1(0.5 \%)$ \\
\hline insomnia & $3(1 \%)$ & $1(0.5 \%)$ \\
\hline Rash & $3(1 \%)$ & $1(0.5 \%)$ \\
\hline AV Block Second Degree & $2(0.6 \%)$ & - \\
\hline
\end{tabular}

The following table presents the most common adverse reactions reported in placebo-controlled trials in patients receiving CARDIZEM CD up to $360 \mathrm{mg}$ with rates in placebo patients shown for comparison.

\begin{tabular}{lcc} 
ADVERSE REACTION & $\begin{array}{c}\text { CARDIZEM CD } \\
\mathrm{N}=324\end{array}$ & $\begin{array}{c}\text { PLACEBO } \\
\mathrm{N}=175\end{array}$ \\
\hline HEADACHE & $9.0 \%$ & $8.0 \%$ \\
BRADYCARDIA & $4.3 \%$ & $2.3 \%$ \\
EDEMA & $3.7 \%$ & $2.3 \%$ \\
DCZZINESS & $3.1 \%$ & $3.4 \%$ \\
ECG ABNORMAUTY & $3.1 \%$ & $2.9 \%$ \\
AV BLOCK FIRST DEGREE & $2.2 \%$ & $\overline{1}$ \\
ASTHENIA & $1.9 \%$ & $1.7 \%$
\end{tabular}

In cinical triak of CARDIZEM CD Capsules, CARDIZEM Tablets, and CARDIZEM SR Capsules involving over 3000 patients, the most common events (ie, greater than $1 \%$ ) were edema $(4.9 \%)$, headache $(4.9 \%)$, dizziness $(3.5 \%)$, asthen $(2.7 \%)$, first-degree AV block $(2.2 \%)$, bradycardia (1.6\%), flushing $(1.5 \%)$, nausea $(1.4 \%)$, rash $(1.3 \%)$, and dispepsia $(1.2 \%)$

In addition, the following events were reported infrequently (less than $1 \%$ )

Cardiovascular: Angina, arthythmia, AV block (second-or third-degree), bundle branch block, congestive heart falure, ECG abnomalities, hypotension, palpitations, sncope, tachycardia, ventricular extrasstolies.

Nervous System: Abnormal dreams, amnesia, depression, gait abnormality hallucinations, insomnia, nervousness, paresthesia, personality change,

Gastrointestinal: Anorevia, constipation, diarnhea, dry mouth, dysgeusia, mid elevations of SGOT, SGPT, LDH, and alkaline phosphatase (see hepatic wamings), thirst, vomiting, weight increase.

Dematologica: Petechiae, photosensitvity, pruitus, urtican Other: Amblyopia, CPK increase, dyspnea, epistaxis, eye irritation, hyperglycemia, hyperuricemia, impotence, muscle cramps, nasa The following postmarketing events have been reported infrequently in patients receiving CARDIZEM: alopecia, erythema multiforme, exfoliative dermatitis, extrapyramidal symptoms, gingival hyperplasia, hemolytic anemia increased bleeding time, leukopenia, purpura, retinopathy, an thrombocytopenia. In addition, events such as myocardial infarction have been observed which are not readily distinguishable from the natural history of the disease in these patients. A number of well-documented cases of generalized rash, characterized as leukocytoclastic vasculitis, have been reported However, a definitive cause and effect relationship between these events and CARDIZEM therapy is yet to be established.

HOW SUPPUED

CARDIZEME CD (diliazem hydrochlonide) is avalable as capsules of $180 \mathrm{~ms}, 240$ $\mathrm{ms}$, and $300 \mathrm{mg}$ in bottles of 30 and 90 , and in UDPO packages of 100 CAROZEMO SR (ditiazem hydrochionide) is avalable as sustained release capsules of $60 \mathrm{mg}, 90 \mathrm{~ms}$, and $120 \mathrm{mg}$ in bottes of 100 , and in $U 0 \mathrm{PO}$ packages of 100 . Product information as of October 1991

References: 1. Dats on the Maron Merefl Dow inc 2. Gamer IA Matison as 